\title{
RANCANG BANGUN VISUALISASI PEMBELAJARAN BERBASIS ANDROID UNTUK ANAK
}

\author{
${ }^{1}$ Sam'ani, ${ }^{2}$ Muhammad Haris Qamaruzzaman \\ ${ }^{12}$ Ilmu Komputer, Universitas Muhammadiyah Palangkaraya \\ Jl. RTA. Milono Km. 1,5 Palangkaraya, Kalimantan Tengah \\ Email :sam.umpalangkaraya@gmail.com, harisqamaruzzaman@yahoo.co.id,
}

(Diterima: 22 Mei 2019, direvisi: 31 Agustus 2019, disetujui: 4 September 2019)

\begin{abstract}
ABSTRAK
Dalam upaya peningkatan kualitas pembelajaran diperlukan penggunaan teknologi informasi dalam media pembelajaran. Penggunaan teknologi informasi dan media dalam pembelajaran dapat membentuk atmosfer pembelajaran di mana siswa dapat aktif berpartisipasi. Saat ini, anak-anak sudah semakin familiar dan lekat dengan yang namanya smartphone ataupun tablet. Perkembangan teknologi piranti mobile yang didukung oleh internet dengan dukungan salah satu sistem operasi mobile yang sangat populer yaitu android, menciptakan akses di setiap waktu dan tempat. Peranti mobile menjadi semakin pintar dan dibutuhkan pada setiap bidang tidak terkecuali bidang Pendidikan bagi anak. Perumusan masalah pada penelitian ini adalah bagaimana menghasilkan visualisasi pembelajaran berbasis android bagi anak-anak usia $6-8$ tahun. Permodelan pengembangan perangkat lunak menggunakan Waterfall yang terdiri dari tahap proses perencanaan, analisis, desain, implementasi, pengujian dan pemeliharaan. Permodelan sistem menggunakan UML (Unified Modeling Language). Sistem dikembangkan dengan menggunakan Eclipse sebagai tools pengembangan aplikasinya. Sistem yang dihasilkan akan menyajikan pembelajaran mengenalkan huruf, angka, warna, buah, sayuran, hewan, pekerjaan, kendaraan dan disertai kuis tebak gambar secara visual dan multimedia sehingga dapat membantu merangsang otak anak-anak usia $6-8$ tahun yang masih sangat peka terhadap apa yang dilihat dan didengarnya.
\end{abstract}

Keywords: Visualisasi Pembelajaran, Anak, Waterfall.

\section{PENDAHULUAN}

Pendidikan bertugas untuk menyiapkan peserta didik agar dapat mencapai peradaban yang maju melalui perwujudan suasana belajar yang kondusif, menarik mencerahkan, dan kreatif [1]. Dalam dunia pendidikan perkembangan teknologi informasi mulai dirasa mempunyai dampak yang positif karena dengan berkembangnya teknologi informasi dunia pendidikan mulai memperlihatkan perubahan yang cukup signifikan. Banyak hal yang dirasa berbeda dan berubah dibandingkan dengan cara yang berkembang sebelumnya. Saat sekarang ini jarak dan waktu bukanlah sebagai masalah yang berarti untuk mendapatkan ilmu, berbagai aplikasi tercipta untuk memfasilitasinya.

Perkembangan teknologi piranti mobile yang didukung oleh internet dengan dukungan salah satu sistem operasi mobile yang sangat populer yaitu android, menciptakan akses di setiap waktu dan tempat [2]. Peranti mobile menjadi semakin pintar dan dibutuhkan pada setiap bidang tidak terkecuali bidang pendidikan bagi anak. Penggunaan media sebagai pendamping dalam proses pembelajaran pendidikan dibutuhkan untuk mengatasi permasalahan yang muncul dalam proses pembelajaran karena keterbatasan waktu, tempat dan benda [3].

Saat ini, anak-anak sudah semakin familiar dan lekat dengan yang namanya smartphone ataupun tablet [4]. Namun, sisi buruk dari perkembangan teknologi yang semakin canggih tersebut, membuat anak-anak susah belajar dan memilih main game terus hingga kecanduan. Agar anak-anak tidak terlalu over dalam bermain gadget dan melupakan belajarnya, perlu dikembangkan suatu aplikasi bernuansa edukasi di smartphone atau tablet agar anak-anak tidak hanya bermain game saja, tapi juga menambah ilmu pengetahuannya. Sistem yang dihasilkan akan menyajikan pembelajaran mengenalkan huruf, angka, warna, buah, sayuran, hewan, pekerjaan, kendaraan dan disertai kuis tebak gambar secara visual dan multimedia dalam 2 (dua) bahasa yaitu Bahasa Indonesia dan Inggris, sehingga dapat membantu 
merangsang otak anak-anak usia $6-8$ tahun yang masih sangat peka terhadap apa yang dilihat dan di dengarnya.

\section{TINJAUAN PUSTAKA}

Beberapa hasil penelitian yang dijadikan sebagai referensi pada penelitian ini, yaitu : Penelitian relevan yang pernah dilakukan tentang Pengenalan Bahasa Inggris Untuk Anak Melalui Aplikasi Edukasi Berbasis Android. Kesimpulan atau hasil dari penelitian ini adalah berupa aplikasi edukasi bahasa Inggris dengan harapan dapat membantu menunjang daya ingat anak-anak yang masih sangat peka terhadap apa yang dilihat dan di dengarnya terutama dalam pembelajaran Bahasa Inggris. Aplikasi ini mengenalkan nama-nama buah-buahan, furniture, kendaraan dan bagian tubuh manusia. Dengan diikuti pengucapan namanya dalam Bahasa Inggris saja [5].

Penelitian tentang pembelajaran khusus huruf multimedia dengan Bahasa Inggris berbasis Android pernah dilakukan. Kesimpulan dari penelitian tersebut adalah menghasilkan sistem pembelajaran huruf dengan multimedia diperuntukkan bagi anak 6-9 tahun dalam Bahasa Inggris [6]. Kemudian penelitian tentang Rancang Bangun Aplikasi Pembelajaran Rambu-Rambu Lalu Lintas Berbasis Android Untuk Siswa Sekolah Dasar telah menghasilkan sebuah aplikasi pembelajaran rambu-rambu lalu lintas bagi anak usia 7-12 tahun [7].

Semua penelitian yang telah dihasilkan sebelumnya dan penelitian yang dibangun ini adalah samasama bertujuan sebagai media pembelajaran bagi anak Sekolah Dasar dan berbasis Android. Namun pada penelitian ini isi/konten yang ditampilkan lebih beragam yaitu menyajikan pembelajaran mengenalkan huruf, angka, warna, buah, sayuran, hewan, pekerjaan, kendaraan dan disertai kuis tebak gambar secara visual dan multimedia dalam 2 (dua) bahasa yaitu Bahasa Indonesia dan Inggris.

\section{METODE PENELITIAN}

Penelitian dan pengembangan bertujuan menghasilkan produk/sistem tertentu dan menguji efektifitas produk/sistem tersebut [8]. Metode pengembangan perangkat lunak System Development Life Cycle (SDLC) dengan pendekatan pengembangan model air terjun (waterfall) digunakan dalam penelitian ini. Model ini merupakan salah satu model yang banyak digunakan dalam pengembangan perangkat lunak yang terdiri dari beberapa tahapan, antara lain yaitu:

1) Perencanaan dan Analisis

Pada tahapan ini berupa pengumpulan data awal yang terdiri dari: pengamatan yaitu pengumpulan data dengan melakukan pengamatan langsung terhadap sampel data yang diperlukan dalam hal ini berlokasi di SDN Bereng Kajang I Jl. Trans Kalimantan Km 34 Tumbang Nusa, Kabupaten Pulang Pisau. Wawancara yaitu pengumpulan data dengan melakukan wawancara atau tanya jawab secara langsung terhadap guru-guru SDN Bereng Kajang I terutama guru kelas 1, 2 dan 3. Serta Literatur yaitu pengumpulan data dengan melakukan studi pustaka mencakup buku-buku teks, jurnal, prosiding, artikel, diktat, makalah dan buku petunjuk teknis terpadu serta literatur lain baik berupa cetak maupun daring

2) Perancangan/ Desain

Dalam merancang sistem pada penelitian ini menggunakan permodelan sistem UML (Unified Modeling Language)

3) Implementasi

Sistem pada penelitian ini dibangun menggunakan Bahasa pemrograman Java, aplikasi Eclipse yang merupakan sebuah IDE (Integrated Development Environment) untuk mengembangkan perangkat lunak, Software Development Kit (SDK ) merupakan tools API (Aplication Programming Interface) yang diperlukan untuk memulai mengembangkan aplikasi pada platform Android menggunakan bahasa pemrograman java, serta ADT/Plugins Eclipse adalah kepanjangan dari Android Development Tools yang menjadi penghubung antara IDE Eclipse dengan Android $S D K[9]$ 


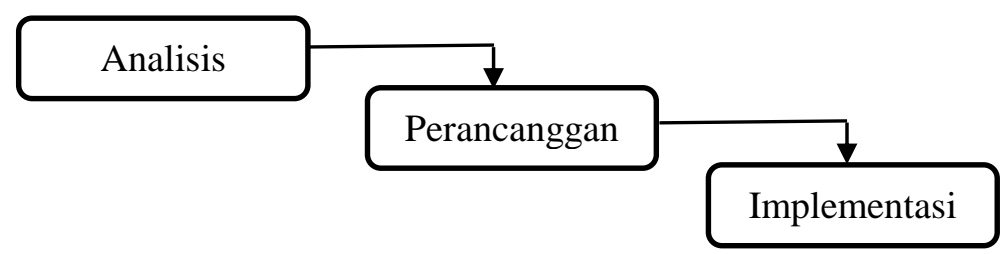

Gambar 1 Metode pengembangan perangkat lunak [10].

\section{HASIL DAN PEMBAHASAN}

\subsection{Analisis}

Selama ini penyampaian pembelajaran yang disampaikan oleh guru kepada siswa masih terfokus menggunakan buku-buku pelajaran, hal yang terkadang membuat siswa ada perasaan bosan untuk belajar [11]. Terlebih lagi untuk siswa kelas 1, 2 dan 3 (berumur 6-8 tahun) sekolah dasar yang masih mempelajari pelajaran dasar seperti huruf, angka, warna dan sebagainya. Sehingga diperlukan sebuah media pembelajaran interaktif yang dapat membantu merangsang otak anak-anak usia $6-8$ tahun yang masih sangat peka terhadap apa yang dilihat dan di dengarnya. Sistem yang dihasilkan ini akan menyajikan pembelajaran mengenalkan huruf, angka, warna, buah, sayuran, hewan, pekerjaan, kendaraan dan disertai kuis tebak gambar secara visual dan multimedia dalam 2 (dua) bahasa yaitu Bahasa Indonesia dan Inggris.

\subsection{Rancangan Sistem}

Penelitian ini menggunakan UML (Unified Modeling Language) sebagai permodelan sistem. Unified modeling Langguage (UML) adalah "bahasa standar untuk penulisan cetak biru perangkat lunak. UML dapat digunakan untuk memvisualisasikan, menentukan, mengonstruksi, dan mendokumentasikan artefak-artefak suatu system Software intensive" [12]. Model UML yang digunakan dalam perancangan dan pembuatan aplikasi ini yaitu terdiri dari :

\subsubsection{Use Case Diagram}

Use Case Diagram merupakan gambaran dari beberapa interaksi antar komponen yang terdapat pada sebuah aplikasi yang akan dibangun [13] dan digunakan dengan tujuan untuk mengetahui fungsi apa saja yang ada di dalam sebuah sistem dan siapa saja yang berhak menggunakan fungsifungsi itu seperti terlihat pada.gambar 2 berikut :

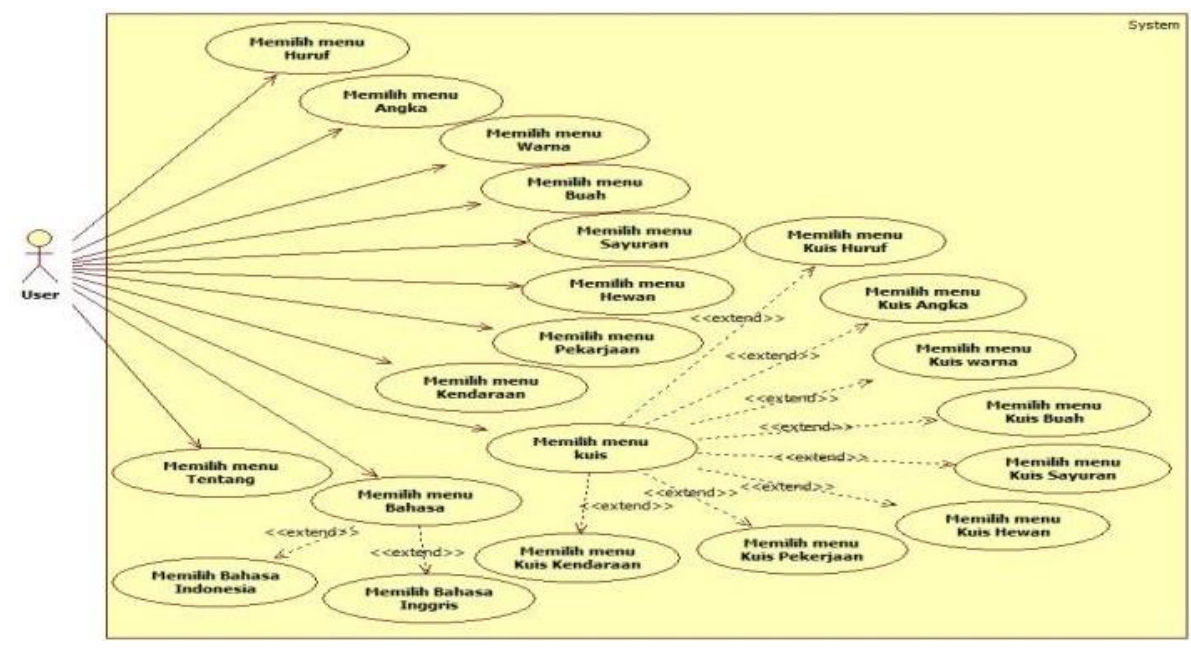

Gambar 2 Use case diagram 


\subsubsection{Class Diagram}

Class diagram adalah suatu diagram yang memperlihatkan atau menampilkan struktur sebuah sistem dari segi pendefinisian kelas-kelas yang akan dibuat untuk membangun sistem [14]. Gambar 3 berikut merupakan Class Diagram sistem yang dibangun :

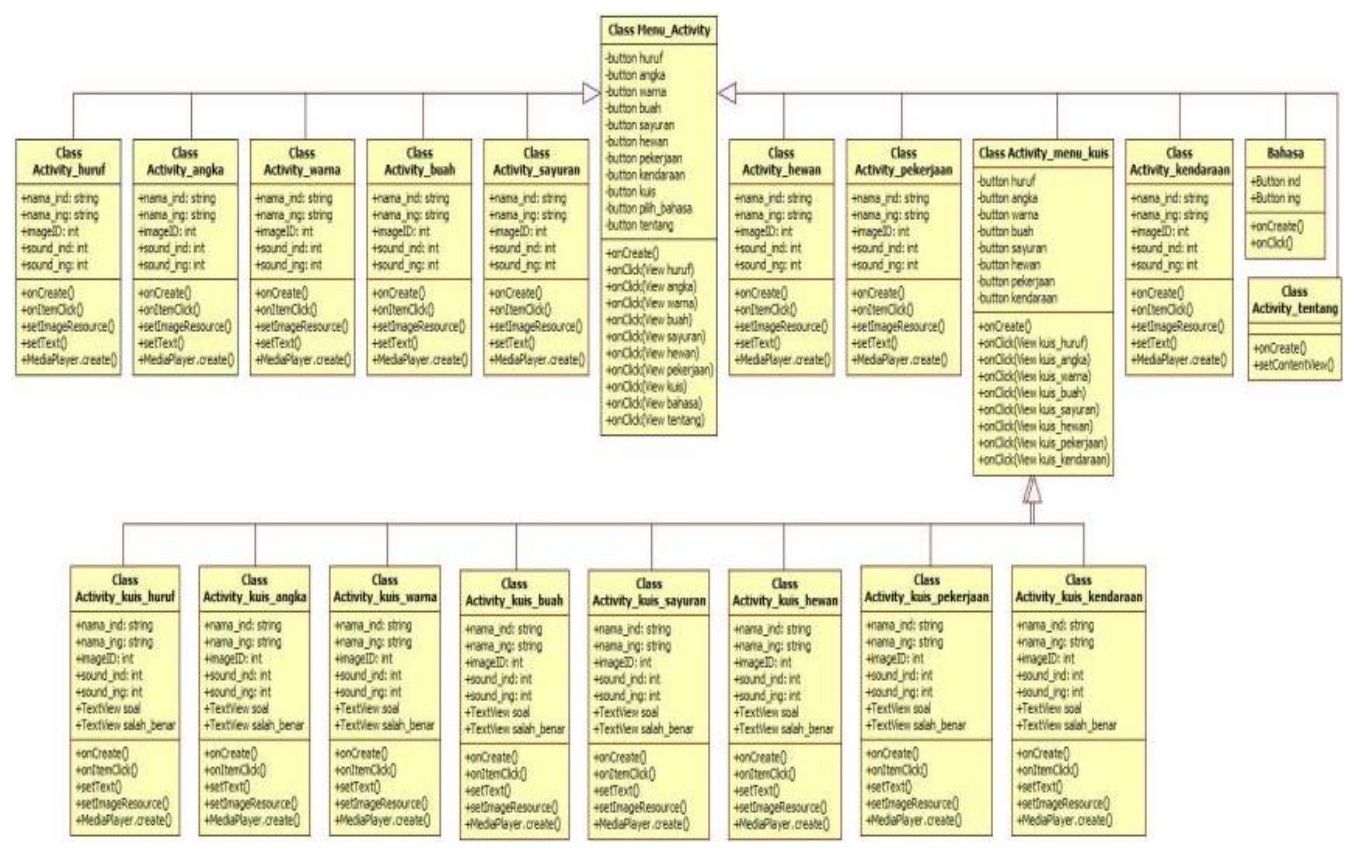

Gambar 3 Class diagram sistem

Berikut penjelasan tentang class diagram sistem pada penelitian ini :

Tabel 1 Penjelasan Class Diagram

\begin{tabular}{|c|c|}
\hline Nama Class & Keterangan \\
\hline Class_menu_Activity & $\begin{array}{l}\text { Class_menu_Activity merupakan class yang memuat kode program } \\
\text { dimana terdapat method untuk memanggil class-class lainya. }\end{array}$ \\
\hline Class Activity_huruf & $\begin{array}{l}\text { Class Activity_huruf merupakan class yang berisi code program dimana } \\
\text { terdapat method untuk menampilkan gambar-gambar huruf, } \\
\text { menampilkan teks nama huruf dan memutar suara nama huruf. }\end{array}$ \\
\hline Class Activity_angka & $\begin{array}{l}\text { Class Activity_angka merupakan class yang berisi code program dimana } \\
\text { terdapat method untuk menampilkan gambar-gambar angka, } \\
\text { menampilkan teks nama angka dan memutar suara nama angka. }\end{array}$ \\
\hline Class Activity_warna & $\begin{array}{l}\text { Class Activity_ warna merupakan class yang berisi code program } \\
\text { dimana terdapat method untuk menampilkan gambar-gambar warna, } \\
\text { menampilkan teks nama warna dan memutar suara nama warna. }\end{array}$ \\
\hline Class Activity_buah & $\begin{array}{l}\text { Class Activity_buah merupakan class yang berisi code program dimana } \\
\text { terdapat method untuk menampilkan gambar-gambar warna, } \\
\text { menampilkan teks nama warna dan memutar suara nama warna. }\end{array}$ \\
\hline Class Activity_sayuran & $\begin{array}{l}\text { Class Activity_sayuran merupakan class yang berisi code program } \\
\text { dimana terdapat method untuk menampilkan gambar-gambar sayuran, } \\
\text { menampilkan teks nama sayuran dan memutar suara nama sayuran. }\end{array}$ \\
\hline Class Activity_hewan & $\begin{array}{l}\text { Class Activity_hewan merupakan class yang berisi code program dimana } \\
\text { terdapat method untuk menampilkan gambar-gambar hewan, } \\
\text { menampilkan teks nama hewan dan memutar suara nama hewan. }\end{array}$ \\
\hline Class Activity_pekerjaan & $\begin{array}{l}\text { Class Activity_pekerjaan merupakan class yang berisi code program } \\
\text { dimana terdapat method untuk menampilkan gambar-gambar pekerjaan, } \\
\text { menampilkan teks nama pekerjaan dan memutar suara nama pekerjaan. }\end{array}$ \\
\hline
\end{tabular}




\begin{tabular}{|c|c|}
\hline Nama Class & Keterangan \\
\hline Class Activity_kendaraan & $\begin{array}{l}\text { Class Activity_ kendaraan merupakan class yang berisi code program } \\
\text { dimana terdapat method untuk menampilkan gambar-gambar kendaraan, } \\
\text { menampilkan teks nama kendaraan dan memutar suara nama kendaraan. }\end{array}$ \\
\hline Class & Class Activity_menu_kuis merupakan class yang memuat kode program \\
\hline Activity menu kuis & dimana terdapat method untuk memanggil class-class kuis lainya. \\
\hline Bahasa & $\begin{array}{l}\text { Bahasa merupakan sebuah dialog yang berisi code program untuk } \\
\text { merubah bahasa aplikasi }\end{array}$ \\
\hline Class Activity_tentang & $\begin{array}{l}\text { Class Activity_tentang merukan class yang berisis kode program untuk } \\
\text { menampilkan halaman tentang }\end{array}$ \\
\hline Class & Class Activity_kuis_huruf merupakan class yang berisi code program \\
\hline Activity_kuis_huruf & $\begin{array}{l}\text { dimana terdapat method untuk menampilkan teks pertanyaan, memutar } \\
\text { suara pertanyaan, dan menampilkan gambar-gambar huruf, }\end{array}$ \\
\hline $\begin{array}{l}\text { Class Activity_ } \\
\text { kuis_angka }\end{array}$ & $\begin{array}{l}\text { Class Activity_kuis_angka merupakan class yang berisi code program } \\
\text { dimana terdapat method untuk menampilkan teks pertanyaan, memutar } \\
\text { suara pertanyaan, dan menampilkan gambar-gambar angka, }\end{array}$ \\
\hline $\begin{array}{l}\text { Class Activity } \\
\text { kuis_warna }\end{array}$ & $\begin{array}{l}\text { Class Activity_kuis_warna merupakan class yang berisi code program } \\
\text { dimana terdapat method untuk menampilkan teks pertanyaan, memutar } \\
\text { suara pertanyaan, dan menampilkan gambar-gambar angka }\end{array}$ \\
\hline $\begin{array}{l}\text { Class Activity } \\
\text { kuis_buah }\end{array}$ & $\begin{array}{l}\text { Class Activity_kuis_buah merupakan class yang berisi code program } \\
\text { dimana terdapat method untuk menampilkan teks pertanyaan, memutar } \\
\text { suara pertanyaan, dan menampilkan gambar-gambar buah }\end{array}$ \\
\hline $\begin{array}{l}\text { Class Activity_ } \\
\text { kuis_sayuran }\end{array}$ & $\begin{array}{l}\text { Class Activity_kuis_sayuran merupakan class yang berisi code program } \\
\text { dimana terdapat method untuk menampilkan teks pertanyaan, memutar } \\
\text { suara pertanyaan, dan menampilkan gambar-gambar sayuran }\end{array}$ \\
\hline $\begin{array}{l}\text { Class Activity_ } \\
\text { kuis_hewan }\end{array}$ & $\begin{array}{l}\text { Class Activity_kuis_hewan merupakan class yang berisi code program } \\
\text { dimana terdapat method untuk menampilkan teks pertanyaan, memutar } \\
\text { suara pertanyaan, dan menampilkan gambar-gambar hewan }\end{array}$ \\
\hline $\begin{array}{l}\text { Class Activity_ } \\
\text { kuis_pekerjaan }\end{array}$ & $\begin{array}{l}\text { Class Activity_kuis_pekerjaan merupakan class yang berisi code } \\
\text { program dimana terdapat method untuk menampilkan teks pertanyaan, } \\
\text { memutar suara pertanyaan, dan menampilkan gambar-gambar pekerjaan }\end{array}$ \\
\hline $\begin{array}{l}\text { Class Activity_ } \\
\text { kuis_kendaraan }\end{array}$ & $\begin{array}{l}\text { Class Activity_kuis_kendaraan merupakan class yang berisi code } \\
\text { program dimana terdapat method untuk menampilkan teks pertanyaan, } \\
\text { memutar suara pertanyaan, dan menampilkan gambar-gambar kendaraan }\end{array}$ \\
\hline
\end{tabular}

\subsubsection{Activity Diagram}

Activity Diagram menggambarkan workflow (aliran kerja) atau aktivitas dari sebuah sistem [15].

Berikut gambar 4 memperlihatkan activity diagram untuk menu utama sistem :

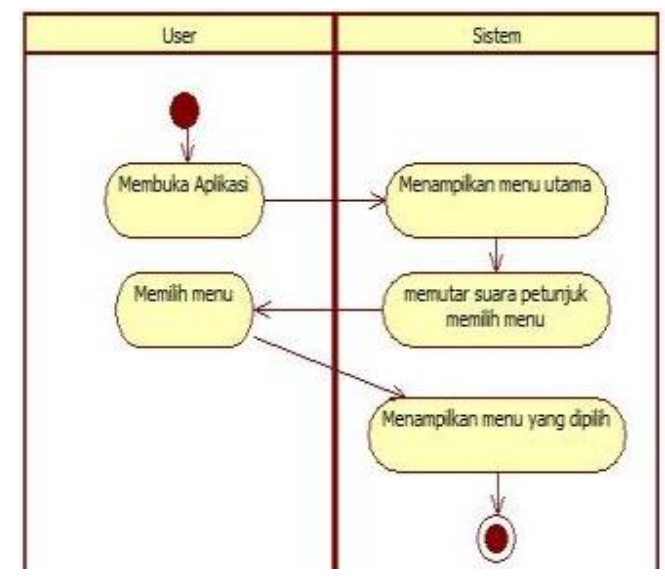

Gambar 4 Activity diagram menu utama 


\subsubsection{Sequence Diagram}

Sequence Diagram menggambarkan kelakuan objek pada use case dengan mendeskripsikan waktu hidup objek dan message yang dikirimkan dan diterima antar objek. Gambar 5 berikut merupakan Sequence Diagram untuk pengenalan huruf dari sistem ini :

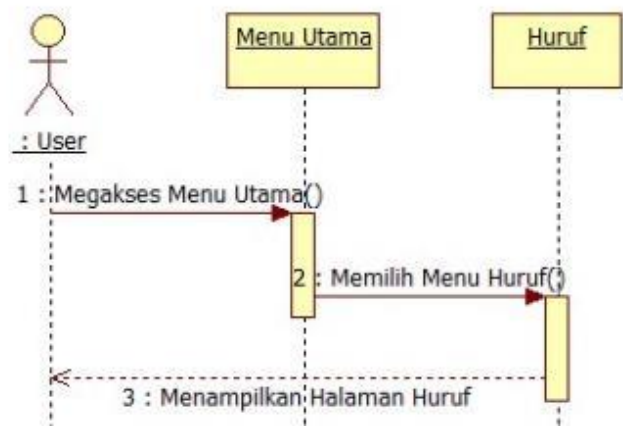

\section{Gambar 5 Sequence diagram huruf}

\subsection{Implementasi Sistem}

Tampilan antar muka menu utama sistem yang dihasilkan penelitian ini dapat dilihat pada Gambar 6 berikut :

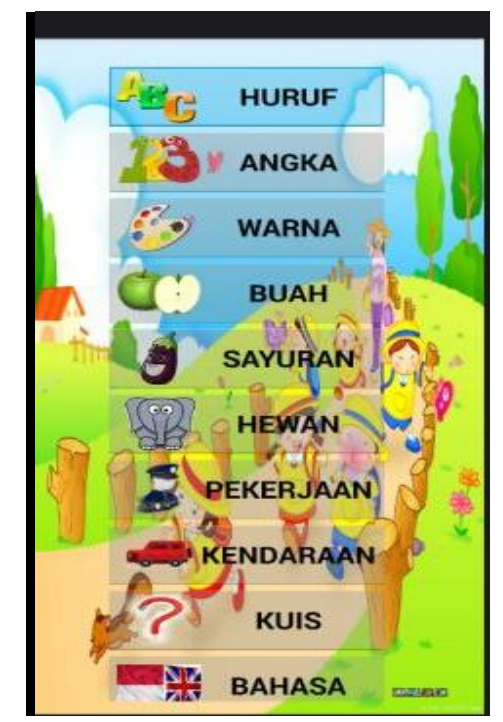

\section{Gambar 6 Halaman menu utama}

Menu utama sistem yang dibangun terdiri dari beberapa menu yang dapat dipilih yaitu : Menu Huruf, Angka, Warna, Buah,, Sayuran, Hewan, Pekerjaan, Kendaraan, Kuis, Bahasa, dan Tentang Aplikasi.

\subsubsection{Menu Huruf}

Menu ini menampilkan grid gambar-gambar huruf yang ketika diklik gambar-gambar yang ada maka akan tampil popup gambar dan suara huruf seperti terlihat pada gambar 7 : 


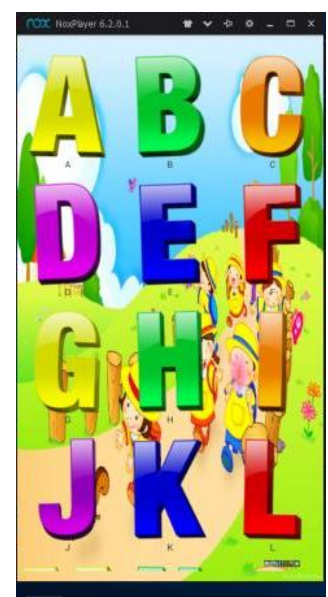

\section{Gambar 7 Tampilan menu huruf}

\subsubsection{Menu Angka}

Menu ini menampilkan grid gambar-gambar angka yang ketika diklik gambar angka yang ada maka akan tampil popup gambar dan suara angka seperti terlihat pada gambar 8 berikut :

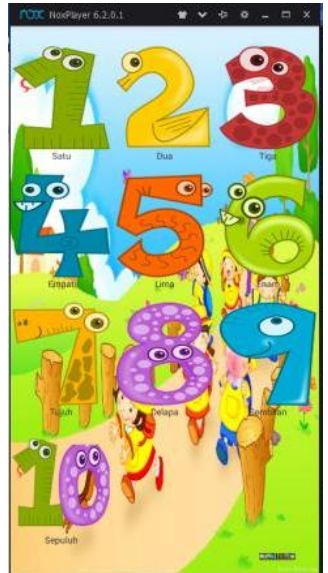

\section{Gambar 8 Tampilan menu angka}

\subsubsection{Menu Warna}

Menu ini menampilkan grid gambar-gambar warna berbentuk balon yang ketika diklik gambar balon warna yang ada maka akan tampil popup gambar dan suara warna yang terpilih seperti terlihat pada Gambar 9 berikut :

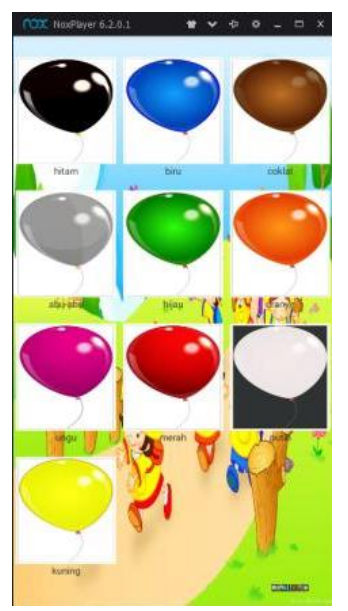

\section{Gambar 9 Tampilan menu warna}




\subsubsection{Menu Buah}

Menu ini menampilkan grid buah-buahan yang ketika diklik gambar buah yang ada maka akan tampil popup gambar dan suara nama buah yang terpilih seperti terlihat pada gambar 10 :

\subsubsection{Menu Sayuran}

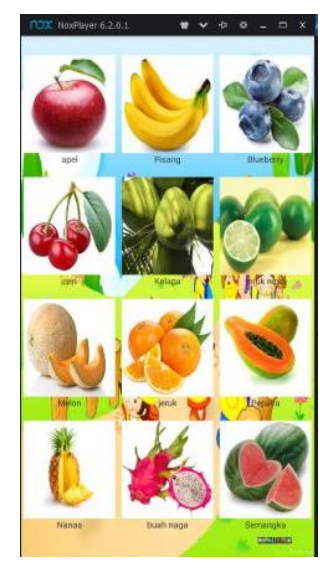

\section{Gambar 10 Tampilan menu buah}

Menu ini menampilkan grid sayuran yang ketika diklik gambar sayuran tersebut maka akan tampil popup gambar dan suara nama sayuran yang terpilih seperti terlihat pada gambar 11 :

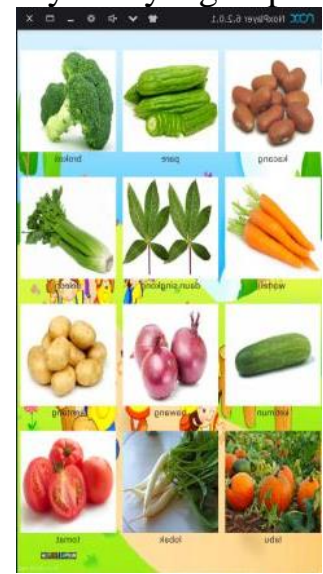

\section{Gambar 11 Tampilan menu sayuran}

\subsubsection{Menu Hewan}

Menu ini menampilkan grid hewan yang ketika diklik gambar hewan tersebut maka akan tampil popup gambar dan suara nama hewan yang terpilih seperti terlihat pada gambar 12 :

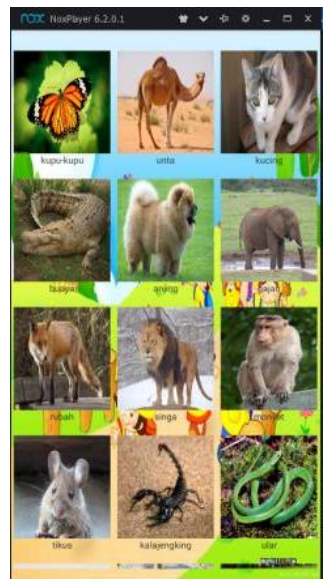

Gambar 12. Tampilan menu hewan 


\subsubsection{Menu Pekerjaan}

Menu ini menampilkan grid pekerjaan yang ketika diklik gambar tersebut maka akan tampil popup gambar dan suara jenis pekerjaan yang terpilih seperti terlihat pada gambar 13 :

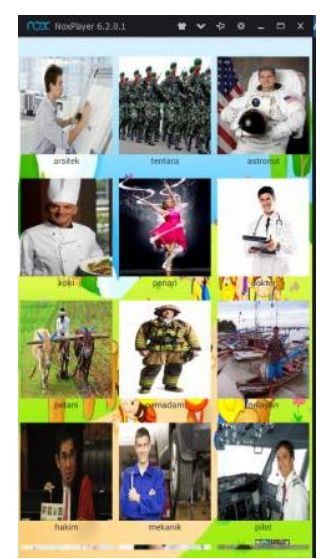

\section{Gambar 13 Tampilan menu pekerjaan}

\subsubsection{Menu Kendaraan}

Menu ini menampilkan grid kendaraan yang ketika diklik gambar tersebut maka akan tampil popup gambar dan suara jenis kendaraan yang terpilih seperti terlihat pada gambar 14 :

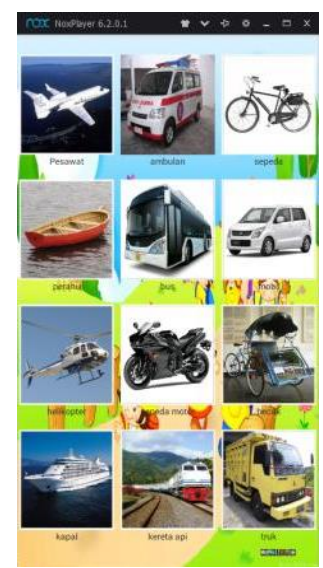

\subsubsection{Menu Kuis}

\section{Gambar 14 Tampilan menu kendaraan}

Menu ini menampilkan kuis tentang huruf, angka, warna, buah, sayuran, hewan, pekerjaan, dan kendaraan seperti terlihat pada Gambar 15 :

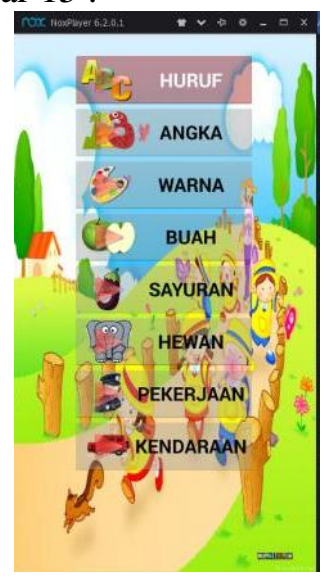

Gambar 15 Tampilan menu kuis 


\subsubsection{Menu Bahasa}

Menu ini menampilkan pilihan bahasa yang bisa dipilih yaitu Bahasa Indonesia atau Inggris seperti terlihat pada gambar 16 :

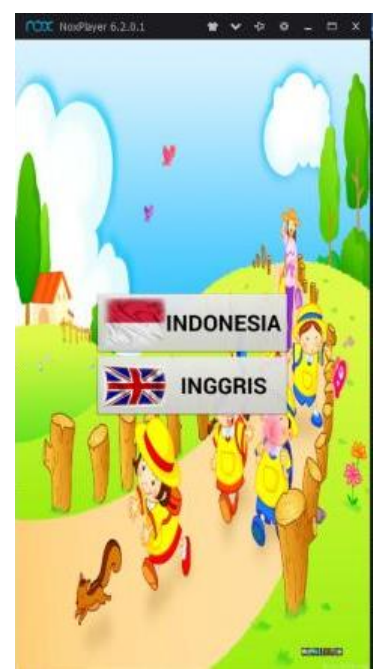

\section{Gambar 16 Tampilan menu bahasa}

\subsubsection{Menu Tentang}

Menu ini menampilkan informasi tentang sistem aplikasi yang dibuat seperti terlihat pada gambar 17 berikut :

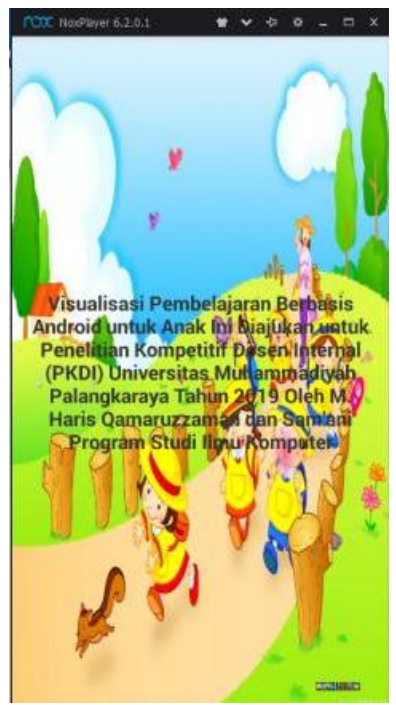

\section{Gambar 17 Tampilan menu tentang}

\section{PENUTUP}

Sistem visualisasi pembelajaran ini dirancang dengan permodelan pengembangan perangkat lunak air terjun (Waterfall, permodelan sistem menggunakan UML (Unified Modeling Language) dan dibangun dengan bahasa pemrograman Java. Sistem yang dihasilkan dapat menyajikan pembelajaran tentang huruf, angka, warna, buah, sayuran, hewan, pekerjaan, kendaraan dan disertai kuis tebak gambar secara visual dan multimedia dalam 2 (dua) bahasa yaitu Inggris maupun Indonesia sehingga dapat membantu merangsang otak anak-anak usia $6-8$ tahun yang masih sangat peka terhadap apa yang dilihat dan didengarnya. 


\section{UCAPAN TERIMA KASIH}

Penulis mengucapkan terima kasih kepada Lembaga Penelitian dan Pengabdian Kepada Masyarakat (LP2M) Universitas Muhammadiyah Palangkaraya yang telah mendanai penelitian ini melalui Penugasan Penelitian Kompetitif Dosen Internal (PKDI) untuk tahun anggaran 2019.

\section{REFERENSI}

[1] D. Irsa, R. Wiryasaputra, and S. Primaini, "Perancangan Aplikasi Game Edukasi Pembelajaran Anak Usia Dini Menggunakan Linear Congruent Method ( LCM ) Berbasis Android," Inform. Glob., vol. 6, no. 1, pp. 7-14, 2015.

[2] Sam'ani and M. H. Qamaruzzaman, "Rancang Bangun Aplikasi Kamus Kahayan - Indonesia Ma'ayan Berbasis Web," Sistemasi, vol. 8, no. 1, pp. 55-61, 2019.

[3] A. S. Afrizal, "Aplikasi Pembelajaran Matematika Interaktif Berbasis Multimedia Tingkat Pendidikan Sekolah Dasar Kelas I (Satu)," Tek. Inform., vol. III, no. 2, pp. 10-21, 2015.

[4] Sujiono and Y. N, Konsep Dasar Pendidikan Anak Usia Dini. Jakarta: PT INDEKS, 2013.

[5] D. Marsa and Sardiarinto, "Pengenalan Bahasa Inggris Untuk Anak Melalui Aplikasi Edukasi Berbasis Android," Semin. Nas. Teknol. Inf. dan Komun. 2013 (SENTIKA 2013), vol. 2013, pp. 156-162, 2013.

[6] I. S. A. Mukti, A. S. M. Lumenta, and B. A. Sugiarso, "Rancang Bangun Aplikasi Pembelajaran Untuk Anak Umur 6 - 9 Tahun Berbasis Android," Multimedia, vol. 7, no. 1, pp. 1-6, 2016.

[7] M. A. Syakur and D. R. Anamisa, "Rancang Bangun Aplikasi Pembelajaran Rambu-Rambu Lalu Lintas Berbasis Android Untuk Siswa Sekolah Dasar," vol. 4, no. 1, 2018.

[8] Guritno, Suryo, Sudaryono, and R. Untung, Theory and Application of IT Research. Yogyakarta: Andi Offset, 2011.

[9] Supardi, Semua Bisa Menjadi Programer Android-Basic. Jakarta: Elex Media Komputindo, 2011.

[10] I. Sommerville, Softaware Engineering (Rekayasa Perangkat Lunak). US: Lancaster, 2003.

[11] Sundari and D. Wahyuningsih, "Aplikasi Pembelajaran Pengenalan Huruf, Angka, Warna dan Bentuk Bangun Datar Pada Siswa Kelas 1 SDN 5 Parittiga Berbasis Android," Sisfokom, vol. 04, no. 01, pp. 56-60, 2015.

[12] R. Pressman, Rekayasa Perangkat Lunak Pendekatan Praktisi (Buku Satu Edisi 7). Yogyakarta: Andi Offset, 2012.

[13] M. H. Qamaruzzaman and Sam'ani, "Aplikasi Penuntun Shalat Sunnah Berbasis Android," SAINTEKOM, vol. 6, no. 2, pp. 47-52, 2016.

[14] Sam'ani, "Rancang Bangun Aplikasi Pengawasan Dan Pengendalian Komputer Laboratorium Multimedia STMIK Palangkaraya," J. Sains Komput. dan Teknol. Inf., vol. 1, no. 1, pp. 33-38, 2018.

[15] D. W. Brata, B. Santoso, J. C. Beck, and M. Wade, "Pembelajaran Matematika Dengan Operator Dasar Untuk Anak Sekolah Dasar Berbasis Mobile," Ilm. Inform., vol. 1, no. 1, pp. 46-50, 2016. 